\title{
Benefits of using probiotics as adjuvants in anticancer therapy (Review)
}

\author{
SILVIA VIVARELLI ${ }^{1}$, LUCA FALZONE $^{1}$, MARIA SOFIA BASILE ${ }^{1}$, DARIA NICOLOSI ${ }^{1}$, \\ CARLO GENOVESE $^{1}$, MASSIMO LIBRA ${ }^{1,2}$ and MARIO SALMERI ${ }^{1,2}$ \\ ${ }^{1}$ Department of Biomedical and Biotechnological Sciences; ${ }^{2}$ Research Center for Prevention, \\ Diagnosis and Treatment of Cancer, University of Catania, I-95123 Catania, Italy
}

Received April 17, 2019; Accepted May 30, 2019

DOI: $10.3892 /$ wasj.2019.13

\begin{abstract}
Cancer is the second leading cause of mortality worldwide and the constant search for novel therapeutics aims to increase the overall survival of the affected population. The human microbiota evolves with the host throughout the course of its entire life, as a direct consequence of individual diet and lifestyle habits. The gut microbiota tremendously affects human homeostasis and it has been widely observed that maintaining a healthy gut may prevent diseases, as well as ameliorate pathological conditions. According to the World Health Organization, probiotics may confer a health benefit on the host when administered in adequate amounts. Anticancer therapy often causes severe side-effects, including gastrointestinal toxicity. Several clinical trials have highlighted the efficacy of administering probiotics to cancer patients receiving anticancer care, with proven efficacy in reducing gut-related and life-threatening side-effects. To corroborate the clinical results, recent translational studies have indicated that the specific administration of selected bacterial gut species are capable of improving the immune check-point immunotherapy clinical outcome. Lactobacillus rhamnosus GG (LGG), a model probiotic widely studied in oncology, has been proven to be beneficial when administered during anticancer therapy. In this review, we report the up-to-date clinical advancements obtained following the administration of probiotics during anticancer therapy, with particular focus on the promising probiotic strain LGG.
\end{abstract}

Correspondence to: Professor Massimo Libra, Department of Biomedical and Biotechnological Sciences, University of Catania, Via Santa Sofia 97, I-95123 Catania, Italy

E-mail:m.libra@unict.it

Key words: probiotics, cancer, chemotherapy, radiotherapy, immune-checkpoint inhibitors, integrated therapy, dysbiosis, Lactobacillus rhamnosus GG

\section{Contents}

1. Introduction

2. Gut microbiota and cancer

3. Gut microbiota and anticancer therapy

4. Probiotics as adjuvants of anticancer therapy

5. LGG, a model probiotic for use as an anticancer adjuvant

6. Conclusions

\section{Introduction}

Every exposed human body surface, including the skin, genitourinary, gastrointestinal and respiratory tracts, are heavily colonized by as many as 10-100 trillion microorganisms, including bacteria, fungi, archaea and viruses (1). In the recent years, commensal microorganisms have been identified as key determinants of a host's homeostasis and health (2). In particular, among the human symbiotic microbial populations, the gut microbiota is the most extensively populated, hosting up to $70 \%$ of the microbes inhabiting the whole body (3). Gut microbiota is the name given to the heterogeneous population of commensal microorganisms, inhabiting the gastrointestinal tract, mostly the large intestine. This population constitutes an agent to which we are constantly exposed, at high doses, throughout an entire lifespan (4). The human gut is populated by 1,000 different bacterial species, prevalently belonging to the phyla of Firmicutes and Bacteroidetes (5).

The intestine is the interface between the gut commensal microbiota and the human body (6). On the one hand, the gastrointestinal enteroendocrine cells secrete over 30 different peptide hormones involved in key functions, including gastrointestinal motility, food digestion and neuromodulation (7). It has been demonstrated that gut-secreted hormones are able to modify the gut microbiome composition, as during the response to stress (8-10). On the other hand, the gut microbial population produces or transforms active molecules, which may be sensed by the gastrointestinal cells of the host (8). The derived functional effects range from the modulation of the host's metabolism to the maintenance of gut barrier integrity, xenobiotics metabolism, protection against gastrointestinal pathogens and modulation of the host's immune system (11-14). Notably, certain commensal bacteria produce 
essential micronutrients, including vitamin $\mathrm{K}$ and vitamin $\mathrm{B}$. Additionally, a number of gut commensals can transform amino acids into signaling molecules, as for example glutamate into gamma-amino butyric acid (GABA) or histidine to histamine. Finally, several Bacteroidetes are able to catabolize phenolic compounds, as well as secondary bile acids, moreover to synthetize the anti-diabetics linoleic acid (15). Another class of hormone-like metabolites produced by the human gut commensals is represented by the short chain fatty acids (SCFAs), derived from the bacterial fermentation of dietary fibers (16). The SCFAs, once synthetized in the intestine, are transported to the liver where they are utilized as a key source of energy. Additionally, SCFAs play a role in controlling glucose and the lipid metabolism by affecting the gut epithelial hormone peptide secretion (17).

Given the reported functional crosstalk between the gastrointestinal microbiota and its host, the preservation of the equilibrium in both composition and the relative abundance of the gut microbial population is fundamental for the correct fulfilment of pivotal host's metabolic, as well as immune functions (18-20). Any disequilibrium in this delicate balance may lead to a defective microbiota, a condition known as dysbiosis, mostly linked to several human pathologies, including cancer (21).

The gut microbiome is defined as the whole genome of the host's gut microbiota, and it encodes 100 -fold more genes than the human genome (22). Over the past 10 years, classical fecal-derived microbe cultivation studies have been strongly integrated with metagenomics approaches, combining next-generation sequencing (NGS) with the computational analysis of the $16 \mathrm{~S}$ rRNA amplicons. Progresses in metagenomics studies, together with many advancements in transcriptomics and metabolomics, have allowed the characterization of both a diversity and abundance of the gut microbiome, with the final goal of determining the impact of each individual gut-populating species on the health of the host $(23,24)$. These novel approaches are depicting the deep impact of the microbiome diversity and composition on human health, as disclosed by the Human Microbiome Project and the large number of originating publications (25-28).

A healthy gut microbiome is defined by a functional core of metabolic and other molecular functions, which are not necessarily performed by the same bacterial species in each different individual (29). The term 'probiotic' means pro-life. Probiotics are currently defined by the Food and Agriculture Organization of the United Nations and by the World Health Organization (FAO/WHO) as 'live microorganisms, which, when consumed in adequate amounts, confer a health effect on the host' (30). They are highly present in fermented food and yoghurt. The vast majority of these probiotics are lactic-acid producing, non-pathogenic bacteria, such as Lactobacillus, Streptococcus, Bifidobacterium, Propionibacterium and Enterococcus or non-pathogenic yeasts including Saccharomyces boulardii (30). Probiotics are administered orally and arrive alive in the intestine (30). They are often administered in combination with specific prebiotics (undigestible food specifically metabolized by probiotics), to form synbiotic mixes (31). Health benefits derived from administering probiotics to healthy individuals include improved digestion, immune defense mechanisms and nutrient absorption. Importantly, probiotics have been proven to be able to revert intestinal dysbiosis, which may play a role in the development of several degenerative diseases, as well as chronic diseases, including cancer (32).

A growing amount of clinical studies are currently investigating the impact of probiotics on the treatment of intestinal toxicity during chemotherapy, immunotherapy and radiation, generating promising results. The present review aimed to summarize the up-to-date clinical observations concerning the role played by probiotics administered in association with anticancer therapy.

\section{Gut microbiota and cancer}

The gut microbiota can be considered a factor to which we are exposed throughout an entire lifespan, whereas intestinal dysbiosis has been found to be linked to the tumorigenesis of both local gastro-intestinal cancers and tumors localized in distant sites of the body (33). Both environmental exposure (e.g., to cancerogenic substances or UV radiation) and lifestyle habits significantly influence individual cancer risk (34-37). This risk is associated with the dose, duration and the combination of these exposures among each other, also depending on the individual genetic background (38-43). In fact, neoplasms bear an intrinsic complexity, as they are derived from the stochastic acquisition of driver mutations within genes involved in key processes (including DNA duplication, DNA repair and oxidative stress response). Thanks to the accumulation of mutations over time and space, cancerogenic cells adapt to the hosting organism, therefore transforming from a normal cell into a malignant one (44-47). Moreover, given the stochastic gathering of mutations, together with the intrinsic tumor cellular genomic instability, epigenetics (including altered DNA methylation, as well as miRNA imbalance), transcriptional and post-transcriptional intracellular changes, from one original cancer can lead to the development of a molecularly varied bulk tumor, made of multiple cancer cell clones, each one presenting a differential sensitivity to the anticancer therapies (48-60).

Anticancer therapies are designed with the final goal of being effective in the eradication of the targeted malignancy. As almost every available treatment is toxic towards normal cells, their use may be coupled with toxic side-effects, some of which can compromise the overall survival of the patients (61). Importantly, the intra-tumoral variety is tightly linked to the development of the resistance to therapy, considered the first cause of failure of the available treatments, as well as subsequent tumor relapses (62). To fight the resistance, integrated therapies and personalized approaches, based on the specific genetic features of the malignancy, are in constant development (62).

The host's immune system plays a fundamental role in fighting and eliminating tumor cells (63-65). On their side, malignant cells, thanks to their genetic instability, constantly develop novel strategies with which to escape from immunosurveillance $(63,66)$. Targeted immunotherapy represents a novel anticancer approach, able to boost the host anti-tumor immune response, and, at the same time, help to 'hit' cancer resistance and recurrence mechanisms $(67,68)$.

Taken together, radiotherapy, chemotherapy and immunotherapy, given their general toxicity, can compromise the gut 
microbiome of patients. At the same time, modulating the gut microbiome composition may deeply influence the outcome of patients to therapies (69). It is therefore of utmost importance to develop novel strategies with which to manipulate the gut microbiome, with the main goal of improving the therapeutic outcome of patients, without any associated risk $(70,71)$

\section{Gut microbiota and anticancer therapy}

A dysbiotic gut microbiota deeply influences both cancer pathogenesis and its therapeutic outcome, with the latter tightly connected with the ability of the gut microbiota to metabolize antitumoral compounds, as well as to modulate a host's immune response and inflammation pathways (72). The combination of these two effects explains the strong involvement of the patients' microbiome composition in affecting their final outcome to treatments (73).

As regards the effects of the gut microbiome on the host's immune system, the past year witnessed the publication of marking breakthrough, strongly coupling the patients' microbiome composition with the efficacy of immune checkpoint inhibitors-based immunotherapy (74-76). Immune checkpoint inhibition consists of the administration of therapeutic agents able to block the immune-inhibitory pathway, thus modulating $\mathrm{T}$ cell activation against tumor target cells [i.e., monoclonal antibodies blocking cytotoxic T-lymphocyte-associated antigen 4 (CTLA4), programmed cell death protein 1 (PD1) or programmed death-ligand 1 (PD-L1) targets] $(77,78)$.

In particular, Routy et al (74) observed that patients with melanoma treated with antibiotics along with the anti-PD1/anti-PD-L1 immunotherapy had a lower survival rate. Following the metagenomic fecal analysis, anti-PD1 responders were found enriched in two phyla (Akkermansia and Alistipes). Performing Fecal Microbiota Transplantation (FMT) from patients to germ-free mice, the authors found that Akkermansia muciniphila increased intra-tumoral cytotoxic $\mathrm{T}$ cell infiltrates, thus ameliorating the PD-1 blockade response in mice (74). Similarly, Gopalakrishnan et al (75) carried out the metagenomic analysis on stool samples from patients with melanoma, finding that the anti-PD1 responders' microbiome differed in composition compared with that of non-responders. In fact, there was an increase in the abundance of Clostridiales, Ruminococcaceae and Faecalibacteriae. Functional studies performed with FMT in germ-free mice have further demonstrated how the treatment of mice with the identified bacteria, along with the anti-PD1 therapy, significantly reduced the growth of melanoma (75). Likewise, Matson et al (76), accomplishing the metagenomic analysis of fecal samples from patients with melanoma treated with immune checkpoint inhibitors, found that responders had a different microbiome profile compared to not responders. They identified and functionally proved in vivo the role played by Bifidobacterium longum, Enterococcus faecium and Collinsella aerofaciens in ameliorating anti-PD-L1 efficacy (76).

Taken together, these results provide strong evidence of the pivotal role of selected gut resident strains in modulating the effects of both immunotherapy response and toxicity. Nevertheless, several obstacles still interfere with the robust translation of the described bench results to the bedside. In fact, the gastrointestinal microbiome of each single patient can be either detrimental or beneficial to tumor progression and therapy, depending on the prevailing inhabiting species. Moreover, the fact that often, cancer patients undergoing therapy are immunocompromised, has to be taken into careful consideration, as this delicate condition could lead to the development of defeating infections, due to the proliferation of opportunistic bacterial species. Consequently, it is necessary to carefully analyze both the risks and benefits of probiotics treatments coupled with anticancer therapy, with the final goal of pursuing only beneficial effects, without any safety issues.

\section{Probiotics as adjuvants of anticancer therapy}

Tremendous progress has been made over the past century to improve anti-cancer therapies, significantly reducing detrimental side-effects, with the final goal of improving the compliance of patients (79). Manipulating the intestinal microbiome through the oral delivery of probiotics is used to improve the safety, as well as to reduce the drastic gastrointestinal side-effects, which are often associated with anticancer treatments, mainly diarrhea and mucositis. In fact, probiotics have the great advantage of being inexpensive and are broadly regarded as safe $(80,81)$. Generally, the use of probiotics in clinical practice has demonstrated that probiotics have a broad spectrum of benefits, including the amelioration of antibiotic- and Clostridium difficile-associated diarrhea, as well as respiratory tract infections (82). Repopulating the gut microbiota cancer of patients through the administration of probiotics, re-establishes both the abundance and the functionality of the commensal gut bacteria, which has been possibly depleted after the therapies (83). The main issues of administering probiotics to immunocompromised cancer patients are both the risk of opportunistic infections, as well as the potential transfer of antibiotics resistance $(84,85)$. In spite of this, the administration of probiotics in multiple trials has shown the readjustment of a healthy intestinal microbiota composition, the amelioration of diarrhea and other types of therapy-associated damage to the gastrointestinal system, including mucositis (80). Moreover, probiotics containing the Lactobacillus species have been suggested as food supplements for the prevention of diarrhea and for the relief of mucositis in patients receiving chemotherapy and/or radiation therapy for a pelvic malignancy $(86,87)$.

Fig. 1 summarizes both the benefits and the risks potentially associated with the administration of probiotics as adjuvants during anticancer therapy, highlighting how probiotics may modulate the delicate gut equilibrium, from a dysbiotic towards a healthy and functioning microbiota.

Following this perspective, a growing number of clinical studies are currently ongoing, with the common intent of investigating the therapeutic potential of gut microbiota manipulation in cancer patients through the oral administration of probiotics as food supplements, along with their anticancer treatment. The results from the published clinical trials are encouraging. In 2010, a double-blind clinical trial, performed on cancer patients undergoing colorectal resection, demonstrated the positive effects of probiotic administration on the gut microbiota composition, as well as on the regulation of intestinal immune functions (88). In particular, Lactobacillus johnsonii, administered to patients, was able to adhere to the 


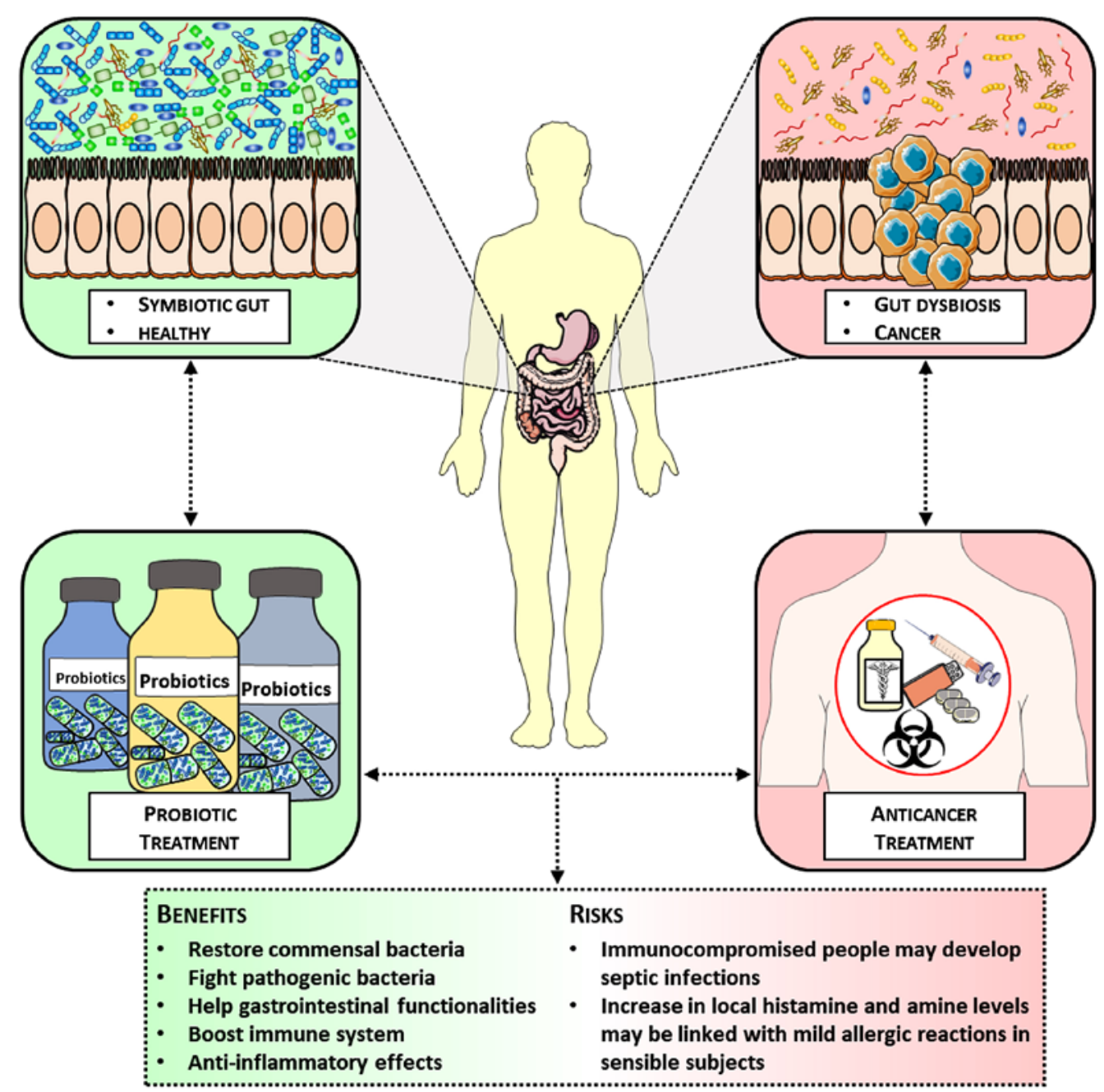

Figure 1. Benefits and risks of associating probiotics with antitumor therapy. Schematic representation of human healthy gut microbiota, populated by symbiotic bacteria (top left square) versus human gut microbiota affected by tumor condition and gut dysbiosis (top right square). Anticancer therapies may negatively affect gut microbiota thus generating a dysbiotic unbalance (bottom right square). Probiotic-based treatments may counterbalance dysbiotic conditions generated by tumor growth and anticancer therapy, with the effect of ameliorating detrimental gastrointestinal therapy-linked side effects, thus re-establishing intestinal symbiosis (bottom left square). The association of probiotics with anticancer therapy have benefits and risks (central bottom rectangle).

colonic mucosa, thereby reducing the concentration of gut pathogens and modulating the local immunity (88). In 2014, a double-blind controlled trial demonstrated the beneficial role of the probiotics Lactobacillus acidophilus and Bifidobacterium longum in reducing radiation-induced diarrhea, when administered to cancer patients receiving pelvic radiation therapy (89). Moreover, in 2015, a clinical trial evaluated the safety and efficacy of a probiotic formula consisting of 10 bacterial strains (including Lactobacilli and Bifidobacteria), orally administered along with irinotecan-based chemotherapy, to patients with colorectal cancer (CRC). The authors successfully found an effective reduction of diarrhea and gastrointestinal dysfunctions in patients receiving the probiotics (90). In 2016, another double-blind, randomized trial demonstrated that patients subjected to $\mathrm{CRC}$ resection exhibited a decreased risk of developing post-operatory irritable bowel syndrome (IBS), when co-treated with a synbiotic mix of prebiotics and probiotics (91). Also in 2016, another randomized trial performed in patients with colon-resected CRC came to the conclusion that Saccaromices bulardii effectively downregulated pro-inflammatory cytokines (92). In 2017, a randomized clinical trial demonstrated how the perioperative administration of a synbiotic mixture of probiotics and prebiotics significantly reduced post-operative infection rates in patients affected by CRC (93).

In addition to the described published findings, a number of clinical trials are currently ongoing to evaluate the safety and the efficacy of using probiotics with anticancer therapy. In fact, regardless the observed beneficial effects, it is of fundamental importance to truly establish the safety of administering probiotics to patients with severe cancer conditions in a larger cohort of cases. The complete list of the currently registered clinical studies (clinicaltrials.gov) untangling the effects of administering probiotics to cancer patients during their therapy, is reported in Table I.

\section{LGG, a model probiotic for use as an anticancer adjuvant}

The probiotic archetype Lactobacillus rhamnosus GG (LGG) represents one of the first studied bacteria in oncology (94). LGG is a gut-resident bacterium which has the ability to restore gut microbial balance, thanks to its anti-inflammatory properties (95-99). The benefits of administering LGG to cancer 
Table I. Clinical studies registered at clinicaltrials.gov involving the use of probiotics in combination with anticancer therapy.

\begin{tabular}{|c|c|c|c|c|c|}
\hline Study ID & Title of the study & Conditions & Interventions & Status & Ref. \\
\hline NCT00936572 & Probiotics In Colorectal Cancer Patients & $\mathrm{CRC}$ & Probiotics (B. longum, L. johnsonii) & $\mathrm{C}$ & (88) \\
\hline NCT01839721 & $\begin{array}{l}\text { Impact of Probiotics BIFILACT } \\
\text { on Diarrhea in Cancer Patients Treated } \\
\text { With Pelvic Radiation }\end{array}$ & CAN & $\begin{array}{l}\text { BIFILACT (L.acidophilus, } \\
\text { B. longum) }\end{array}$ & $\mathrm{C}$ & (89) \\
\hline NCT01410955 & $\begin{array}{l}\text { Prevention of Irinotecan } \\
\text { Induced Diarrhea by Probiotics }\end{array}$ & $\mathrm{CRC}$ & $\begin{array}{l}\text { Colon Dophilus (Lactobacillus spp, } \\
\text { Bifidobacterium spp) }\end{array}$ & $\mathrm{C}$ & (90) \\
\hline NCT01479907 & $\begin{array}{l}\text { Synbiotics and Gastrointestinal Function } \\
\text { Related Quality of Life After } \\
\text { Colectomy for Cancer }\end{array}$ & $\mathrm{CRC}$ & $\begin{array}{l}\text { Synbiotic Forte } \\
\text { (Lactobacillus spp and prebiotics) }\end{array}$ & $\mathrm{C}$ & (91) \\
\hline NCT01609660 & $\begin{array}{l}\text { Impact of Probiotics on the } \\
\text { Intestinal Microbiota }\end{array}$ & $\mathrm{CRC}$ & S. boulardii & $\mathrm{C}$ & (92) \\
\hline NCT01468779 & $\begin{array}{l}\text { Effect of Probiotics in Patients } \\
\text { Undergoing Surgery for } \\
\text { Periampullary Neoplasms }\end{array}$ & $\mathrm{PC}$ & Probiotic formula & $\mathrm{C}$ & (93) \\
\hline NCT03420443 & $\begin{array}{l}\text { Action of Synbiotics on Irradiated GI } \\
\text { Mucosa in CRC Treatment (FIPIREX) }\end{array}$ & $\mathrm{CRC}$ & Synbiotics & $\mathrm{C}$ & \\
\hline NCT01723592 & $\begin{array}{l}\text { Orally Administered Probiotics to Improve } \\
\text { the Quality of the Vaginal Flora of Women } \\
\text { With Breast Cancer and Chemotherapy }\end{array}$ & $\mathrm{BC}$ & Probiotics (Lactobacillus spp) & $\mathrm{C}$ & \\
\hline NCT02771470 & $\begin{array}{l}\text { Intestinal Microflora in Lung } \\
\text { Cancer After Chemotherapy }\end{array}$ & $\mathrm{LC}$ & C. butyricum & $\mathrm{C}$ & \\
\hline NCT01895530 & $\begin{array}{l}\text { Impact of Probiotics in } \\
\text { Modulation of Intestinal Microbiota }\end{array}$ & $\mathrm{CRC}$ & S. boulardii & $\mathrm{C}$ & \\
\hline NCT02021253 & $\begin{array}{l}\text { Influence of Probiotics Administration } \\
\text { Before Liver Resection in Liver Disease }\end{array}$ & $\mathrm{HC}$ & $\begin{array}{l}\text { Lactibiane (B. lactis, L. acidophilus, } \\
\text { L. plantarum, L. salivarius) }\end{array}$ & $\mathrm{C}$ & \\
\hline NCT03531606 & $\begin{array}{l}\text { The Effects of Mechnikov Probiotics } \\
\text { on Symptom and Surgical Outcome }\end{array}$ & $\mathrm{CRC}$ & Probiotics & $\mathrm{C}$ & \\
\hline NCT03782428 & $\begin{array}{l}\text { An Evaluation of Probiotic in the } \\
\text { Clinical Course of Patients With } \\
\text { Colorectal Cancer }\end{array}$ & $\mathrm{CRC}$ & $\begin{array}{l}\text { HEXBIO (L. acidophilus, L. lactis, } \\
\text { L. casei, B. longum, B. bifidum, } \\
\text { B. infantis) }\end{array}$ & $\mathrm{C}$ & \\
\hline NCT03358511 & $\begin{array}{l}\text { Engineering Gut Microbiome } \\
\text { to Target Breast Cancer }\end{array}$ & $\mathrm{BC}$ & $\begin{array}{l}\text { Primal Defense Ultra } \\
\text { (Lactobacillus spp, } \\
\text { Bifidobacterium spp) }\end{array}$ & $\mathrm{O}$ & \\
\hline NCT03785938 & $\begin{array}{l}\text { Mucositis and Infection Reduction } \\
\text { With Liquid Probiotics in Children } \\
\text { With Cancer (MaCROS) }\end{array}$ & PEDC & $\begin{array}{l}\text { Symprove (L. rhamnosus, E. faecium, } \\
\text { L. acidophilus, L. plantarum) }\end{array}$ & $\mathrm{O}$ & \\
\hline NCT02944617 & $\begin{array}{l}\text { Probiotic Yogurt Supplement in } \\
\text { Reducing Diarrhea in Patients With } \\
\text { Metastatic Kidney Cancer Being Treated } \\
\text { With Vascular Endothelial Growth } \\
\text { Factor-Tyrosine Kinase Inhibitor }\end{array}$ & $\mathrm{RCC}$ & Yogurt & $\mathrm{O}$ & \\
\hline NCT03704727 & $\begin{array}{l}\text { The Effects of Probiotics on Intestinal } \\
\text { Permeability in Gastrointestinal } \\
\text { Cancer Patients in Chemotherapy }\end{array}$ & GIC & $\begin{array}{l}\text { VSL3 (Lactobacillus spp, } \\
\text { Bifidobacterium spp) }\end{array}$ & $\mathrm{O}$ & \\
\hline NCT03742596 & $\begin{array}{l}\text { The Effect of Probiotics Supplementation } \\
\text { on the Side Effects of Radiation Therapy } \\
\text { Among Colorectal Cancer Patients }\end{array}$ & $\mathrm{CRC}$ & $\begin{array}{l}\text { Probiotic Formula (Lactobacillus spp, } \\
\text { Bifidobacterium spp) }\end{array}$ & $\mathrm{O}$ & \\
\hline NCT03177681 & $\begin{array}{l}\text { The Effect of Yogurt in Cancer Patient } \\
\text { With Moderate Gastrointestinal Symptoms }\end{array}$ & CAN & Yogurt & $\mathrm{O}$ & \\
\hline NCT02351089 & $\begin{array}{l}\text { Probiotics in Radiation-treated } \\
\text { Gynecologic Cancer (ProRad) }\end{array}$ & GYC & Probiotics & $\mathrm{O}$ & \\
\hline NCT03705442 & $\begin{array}{l}\text { Probiotics as Adjuvant Therapy } \\
\text { in the Treatment of Metastatic }\end{array}$ & $\mathrm{CRC}$ & $\begin{array}{l}\text { Omni-Biotic } 10 \text { (Lactobacillus spp, } \\
\text { Bifidobacterium spp) }\end{array}$ & $\mathrm{O}$ & \\
\hline
\end{tabular}


Table I. Continued.

\begin{tabular}{|c|c|c|c|c|c|}
\hline Study ID & Title of the study & Conditions & Interventions & Status & Ref. \\
\hline NCT03552458 & $\begin{array}{l}\text { Effects of Probiotics in } \\
\text { Preventing Oral Mucositis }\end{array}$ & HAN & L. Reuteri & $\mathrm{O}$ & \\
\hline NCT03518268 & $\begin{array}{l}\text { Vivomixx for Prevention of Bone } \\
\text { Loss in Women With Breast Cancer } \\
\text { Treated With an Aromatase Inhibitor }\end{array}$ & $\mathrm{BC}$ & $\begin{array}{l}\text { Vivomixx (Lactobacillus spp, } \\
\text { Bifidobacterium spp) }\end{array}$ & $\mathrm{O}$ & \\
\hline NCT03574051 & $\begin{array}{l}\text { Microbiota Associated With Iodine- } 131 \\
\text { Therapy and Hypothyroidism }\end{array}$ & $\mathrm{TC}$ & $\begin{array}{l}\text { Probiotics (B. infantis, } \\
\text { L.acidophilus, E.faecalis) }\end{array}$ & $\mathrm{O}$ & \\
\hline NCT03642548 & $\begin{array}{l}\text { Probiotics Combined With Chemotherapy } \\
\text { for Patients With Advanced NSCLC }\end{array}$ & NSCLC & Bifico (B. Coagulans) & $\mathrm{O}$ & \\
\hline NCT02751736 & $\begin{array}{l}\text { The Effect Of Probiotics On Bowel } \\
\text { Function Restoration After Ileostomy } \\
\text { Closure In Patients With Rectal Cancer }\end{array}$ & $\mathrm{CRC}$ & L. plantarum & $\mathrm{O}$ & \\
\hline NCT01790035 & $\begin{array}{l}\text { Probiotic LGG for Prevention of } \\
\text { Side Effects in Patients Undergoing } \\
\text { Chemoradiation for Gastrointestinal } \\
\text { Cancer }\end{array}$ & GIC & L. rhamnosus GG & $\mathrm{O}$ & $(101)$ \\
\hline NCT00197873 & $\begin{array}{l}\text { Lactobacillus rhamnosus in Prevention } \\
\text { of Chemotherapy-related Diarrhoea }\end{array}$ & CRC & L. rhamnosus GG & $\mathrm{O}$ & \\
\hline NCT02544685 & $\begin{array}{l}\text { Prevention of Febrile Neutropenia by } \\
\text { Synbiotics in Pediatric Cancer Patients }\end{array}$ & CAN & $\begin{array}{l}\text { Probio-Fix Inum and corn starch } \\
\text { (L. rhamnosus GG, B. animalis) }\end{array}$ & $\mathrm{O}$ & \\
\hline NCT02819960 & $\begin{array}{l}\text { Prevention of Irinotecan } \\
\text { Induced Diarrhea by Probiotics }\end{array}$ & CAN & $\begin{array}{l}\text { Probio-Fix Inum (L. rhamnosus } \mathrm{GG}, \\
\text { B. animalis) }\end{array}$ & $\mathrm{O}$ & \\
\hline
\end{tabular}

CRC, colorectal cancer; CAN, cancer; PC, periampullary carcinoma; BC, breast cancer; LC, lung cancer; HC, hepatocellular carcinoma; PEDC, pediatric cancer; RCC, renal cell cancer; GIC, gastrointestinal cancer; GYC, gynecological cancer; HAN, head-and-neck cancer; TC, thyroid cancer; NSCLC, non-small cell lung cancer; LGG, Lactobacillus rhamnosus GG; C, closed study; O, ongoing study.

patients is supported by multiple in vitro, in vivo and clinical studies, as recently reviewed by our group (100). Moreover, 70 trials are currently registered at clinicaltial.gov, aiming to specifically determine the effects associated with the administration of LGG in several different conditions (Table II).

In line with these studies, a number of ongoing clinical trials are currently testing both the effectiveness and the safety of administering LGG to cancer patients subjected to anticancer therapy (NCT01790035, NCT00197873, NCT02544685, NCT02819960; Table I). Very recently, pre-results in support of the ongoing clinical trial NCT01790035 have been published. These results clearly show the mechanisms through which LGG is able to selectively protect colon normal cells during radiotherapy protocols, both in vitro and in vivo. LGG functions as a 'time-release capsule', able to deliver radioprotective lipoteichoic acid (LTA) within the intestinal crypts, thereby selectively protecting from the radiation-induced cell death the normal cells, but not the tumor cells (101). Notably, the group demonstrated that LGG-derived LTA activates peri-cryptal macrophages, in turn protecting the epithelial stem cells from radiation-induced apoptosis (101).

In addition to the cited clinical trials, two clinical trials designed by our group are currently opening and are about to be registered at clinicaltrials.gov. The two studies, entitled respectively: 'Maintenance of normal gastrointestinal function with dietary supplement containing Lactobacillus rhamnosus GG in cancer patients treated with cytotoxic chemotherapy and/or targeted therapy' and 'Maintenance of normal gastrointestinal function with dietary supplement containing Lactobacillus rhamnosus GG in patients treated with abdominal or pelvic radiotherapy', will assess the efficacy of LGG daily oral administration in the maintenance of normal gastrointestinal functions within cancer patients, treated either with chemotherapy and/or targeted therapy or abdominal/pelvic radiotherapy.

Once concluded, the currently ongoing clinical studies, will shed light into the efficacy and safety of the use of the promising probiotic, LGG, as an adjuvant in oncology. The studies will assess whether LGG is truly able to protect cancer patients from the detrimental gastrointestinal side-effects usually associated with anticancer therapy.

\section{Conclusions}

The human gut microbiota composition consists of a delicate balance, constantly modulated by several processes affecting the host during the entire lifespan (including aging, diet and lifetime exposure to heterogeneous environmental factors). A healthy microbiota is able to perform core symbiotic functions within his host, in a well-integrated host-microbiota relationship.

Cancer is a condition which tremendously affects the gut microbiota-host equilibrium, both during oncogenesis, as well as concurrently with anticancer therapy. This unbalanced 
Table II. Clinical trials registered at clinicaltrials.gov assessing the benefits of administering LGG in association with a large number of different conditions.

\begin{tabular}{|c|c|c|}
\hline NCT No. & Status & Conditions \\
\hline NCT01922895 & Active & Acute Alcoholic Hepatitis \\
\hline NCT03080818 & Active & Aging \\
\hline NCT03449537 & Active & Allergy Milk \\
\hline NCT03256708 & Active & Antibiotic-Associated Diarrhea \\
\hline NCT03449459 & Active & Chronic Obstructive Pulmonary Disease \\
\hline NCT03587545 & Active & Chronic Rhinosinusitis \\
\hline NCT03647995 & Active & Diarrhea, Clostridium difficile \\
\hline NCT02544685 & Active & Febrile Neutropenia \\
\hline NCT01790035 & Active & Gastrointestinal Neoplasms \\
\hline NCT02640625 & Active & Human Immunodeficiency Virus \\
\hline NCT02748317 & Active & Lower Urinary Tract Symptoms \\
\hline NCT02748356 & Active & Lower Urinary Tract Symptoms \\
\hline NCT03383874 & Active & Mania, Neurotic \\
\hline NCT03215784 & Active & Obesity, Pregnancy, Inflammation \\
\hline NCT03277820 & Active & Otitis Media \\
\hline NCT03196453 & Active & Overweight, Nutrition Disorder \\
\hline NCT02462590 & Active & Pneumonia, Infections, Diarrhea \\
\hline NCT01454661 & Active & Premature Infant \\
\hline NCT00490425 & Completed & Allergic Asthma \\
\hline NCT01901380 & Completed & Allergy, Functional Gastrointestinal Disorders \\
\hline NCT00748748 & Completed & Antibiotic-Associated Diarrhea \\
\hline NCT02711800 & Completed & Anxiety, Abdominal Pain \\
\hline NCT00159523 & Completed & Asthma, Atopic Dermatitis \\
\hline NCT01148667 & Completed & Atopic Dermatitis \\
\hline NCT00325273 & Completed & Atopic Dermatitis, Allergic Rhinitis, Asthma \\
\hline NCT00224432 & Completed & Atopic Dermatitis, Atopic Eczema \\
\hline NCT03078179 & Completed & Caries, Dental \\
\hline NCT01279265 & Completed & Colic, Inflammation \\
\hline NCT02466035 & Completed & Cow’s Milk Allergy \\
\hline NCT02779881 & Completed & Cow’s Milk Allergy \\
\hline NCT01956916 & Completed & Cystic Fibrosis \\
\hline NCT01961661 & Completed & Cystic Fibrosis \\
\hline NCT00318695 & Completed & Eczema, Asthma, Allergic Rhinitis \\
\hline NCT02642289 & Completed & Fibromyalgia \\
\hline NCT01773967 & Completed & Gastroenteritis \\
\hline NCT02144701 & Completed & Graft Versus Host Disease \\
\hline NCT00620412 & Completed & Healthy \\
\hline NCT00934453 & Completed & Healthy \\
\hline NCT03168503 & Completed & Healthy \\
\hline NCT01274598 & Completed & Healthy, Elderly \\
\hline NCT01368029 & Completed & Healthy, Elderly \\
\hline NCT01545349 & Completed & Healthy, Influenza \\
\hline NCT03427515 & Completed & Healthy, Stress-related Problem, Anxiety \\
\hline NCT01969331 & Completed & Helicobacter pylori Infection \\
\hline NCT03307772 & Completed & Herpes Labialis \\
\hline NCT03310294 & Completed & Herpes Labialis \\
\hline NCT01439841 & Completed & HIV-1 Infection \\
\hline NCT01616693 & Completed & Immunity to Oral Vaccines \\
\hline NCT02046512 & Completed & Infection \\
\hline NCT01551186 & Completed & Infectious Disease of Digestive Tract \\
\hline NCT01130792 & Completed & Infectious Gastroenteritis \\
\hline
\end{tabular}


Table II. Continued.

\begin{tabular}{lll}
\hline NCT No. & \multicolumn{1}{c}{ Status } & \\
\hline NCT02230345 & Completed & \multicolumn{1}{c}{ Conditions } \\
NCT01720329 & Completed & Inflammation, Dyslipidemia \\
NCT03100266 & Completed & Influenza \\
NCT01164124 & Completed & Low Back Pain \\
NCT02288572 & Completed & Low Birth Weight \\
NCT01670916 & Completed & Metabolic Syndrome X \\
NCT01868737 & Completed & Necrotizing Enterocolitis \\
NCT02807246 & Completed & Necrotizing Enterocolitis \\
NCT02558192 & Completed & Neonatal Hyperbilirubinemia \\
NCT01870544 & Completed & Nosocomial Infection \\
NCT02444182 & Completed & Obesity \\
NCT00282113 & Completed & Periodontal Health, Dental Plaque Accumulation \\
NCT02180581 & Completed & Premature Infants \\
NCT01229917 & Completed & Respiratory Infections, Gastrointestinal Infections \\
NCT02110732 & Completed & Respiratory Tract Infections \\
NCT01782755 & Completed & Upper Respiratory Infection, Acute Otitis Media \\
NCT00445120 & Completed & Ventilator Associated Pneumonia \\
\end{tabular}

equilibrium is often followed by the dysbiosis of the gut microbiota. Consequently, current research is constantly aiming at identifying methods with which to safely modulate a dysbiotic microbiota, helping to heal detrimental conditions, such as the gastrointestinal side-effects of chemotherapy, radiation therapy and immunotherapy (including mucositis, diarrhea and opportunistic infections).

The administration of probiotics during anticancer therapy is yielding promising clinical results, as it improves gut dysbiosis in cancer patients. Moreover, probiotics have been found capable of significantly ameliorating patients' compliance to treatments, as well as their overall quality of life. Among the characterized probiotics, recent studies have suggested that LGG, administered in vivo, is able to modulate the immune system, reducing the detrimental toxic intestinal effects following pelvic radiotherapy. This result is particularly promising and paves the way towards the auspicious ongoing trials on cancer patients undergoing anticancer treatments.

Despite the already published clinical results reporting the beneficial role of probiotics in alleviating the harmful side-effects of anticancer therapies, care needs to be pursued, as patients are often immunocompromised; therefore, it is important to evaluate the health risks possibly linked to the administration of probiotics to sensitive individuals. In the future, the design of novel experimental trials may undertake a personalized approach, considering the specific clinical and pathological background of each single patient to be enrolled, in order to gain only the positive outcomes of probiotics administration, possibly without any harmful side-effect.

\section{Acknowledgements}

The authors would like to thank the Italian League Against Cancer (LILT) for its support.

\section{Funding}

No funding was received.

\section{Availability of data and materials}

Not applicable.

\section{Authors' contributions}

SV and ML were involved in the conceptualization and design of this review article. LF, MSB and CG were involved in searching the literature for paragraphs 2 and 5. DN and MS were involved in searching the relevant literature and databases for paragraphs 3 and 4. SV and ML were involved in the preparation of the original draft and in the preparation of the figure and tables. SV, LF, MSB, DN, CG, ML and MS reviewed and edited the article. All authors have read and approved the final version of the manuscript.

\section{Ethics approval and consent to participate}

Not applicable.

\section{Patient consent for publication}

Not applicable.

\section{Competing interests}

ML is the PI of a research grant founded by Dicofarm Spa to his University Department. The other authors declare that the research was conducted in the absence of any commercial or financial relationships that could be construed as a potential competing interest. 


\section{References}

1. Ursell LK, Metcalf JL, Parfrey LW and Knight R: Defining the human microbiome. Nutr Rev 70 (Suppl 1): S38-S44, 2012.

2. Zhang YJ, Li S, Gan RY, Zhou T, Xu DP and Li HB: Impacts of gut bacteria on human health and diseases. Int J Mol Sci 16: 7493-7519, 2015.

3. Feng Q, Chen WD and Wang YD: Gut Microbiota: An Integral Moderator in Health and Disease. Front Microbiol 9: 151, 2018.

4. Lynch SV and Pedersen O: The Human Intestinal Microbiome in Health and Disease. N Engl J Med 375: 2369-2379, 2016.

5. Greenhalgh K, Meyer KM, Aagaard KM and Wilmes P: The human gut microbiome in health: Establishment and resilience of microbiota over a lifetime. Environ Microbiol 18: 2103-2116, 2016

6. Neuman H, Debelius JW, Knight R and Koren O: Microbial endocrinology: The interplay between the microbiota and the endocrine system. FEMS Microbiol Rev 39: 509-521, 2015.

7. Ceranowicz P, Warzecha Z and Dembinski A: Peptidyl hormones of endocrine cells origin in the gut--their discovery and physiological relevance. J Physiol Pharmacol 66: 11-27, 2015.

8. Sandrini S, Aldriwesh M, Alruways $M$ and Freestone $P$. Microbial endocrinology: Host-bacteria communication within the gut microbiome. J Endocrinol 225: R21-R34, 2015.

9. Ravussin Y, Koren O, Spor A, LeDuc C, Gutman R, Stombaugh J, Knight R, Ley RE and Leibel RL: Responses of gut microbiota to diet composition and weight loss in lean and obese mice. Obesity (Silver Spring) 20: 738-747, 2012.

10. Queipo-Ortuño MI, Seoane LM, Murri M, Pardo M, Gomez-Zumaquero JM, Cardona F, Casanueva F and Tinahones FJ: Gut microbiota composition in male rat models under different nutritional status and physical activity and its association with serum leptin and ghrelin levels. PLoS One 8: e65465, 2013.

11. Gensollen T, Iyer SS, Kasper DL and Blumberg RS: How colonization by microbiota in early life shapes the immune system. Science 352: 539-544, 2016.

12. Schmidt TSB, Raes J and Bork P: The Human Gut Microbiome: From Association to Modulation. Cell 172: 1198-1215, 2018.

13. Bultman SJ: Emerging roles of the microbiome in cancer. Carcinogenesis 35: 249-255, 2014.

14. Cani PD: Human gut microbiome: Hopes, threats and promises. Gut 67: 1716-1725, 2018.

15. Mohajeri MH, Brummer RJM, Rastall RA, Weersma RK, Harmsen HJM, Faas M and Eggersdorfer M: The role of the microbiome for human health: From basic science to clinical applications. Eur J Nutr 57 (Suppl 1): 1-14, 2018.

16. Fukui $\mathrm{H}, \mathrm{Xu} \mathrm{X}$ and Miwa H: Role of Gut Microbiota-Gut Hormone Axis in the Pathophysiology of Functional Gastrointestinal Disorders. J Neurogastroenterol Motil 24: 367-386, 2018.

17. Clarke G, Stilling RM, Kennedy PJ, Stanton C, Cryan JF and Dinan TG: Minireview: Gut microbiota: the neglected endocrine organ. Mol Endocrinol 28: 1221-1238, 2014.

18. Vaishnava S, Behrendt CL, Ismail AS, Eckmann L and Hooper LV: Paneth cells directly sense gut commensals and maintain homeostasis at the intestinal host-microbial interface. Proc Natl Acad Sci USA 105: 20858-20863, 2008.

19. Belkaid Y and Naik S: Compartmentalized and systemic control of tissue immunity by commensals. Nat Immunol 14: 646-653, 2013.

20. Magnúsdóttir S, Ravcheev D, de Crécy-Lagard V and Thiele I: Systematic genome assessment of B-vitamin biosynthesis suggests co-operation among gut microbes. Front Genet 6: 148, 2015.

21. Carding S, Verbeke K, Vipond DT, Corfe BM and Owen LJ: Dysbiosis of the gut microbiota in disease. Microb Ecol Health Dis 26: 26191, 2015.

22. Grice EA and Segre JA: The human microbiome: Our second genome. Annu Rev Genomics Hum Genet 13: 151-170, 2012.

23. Geva-Zatorsky N, Sefik E, Kua L, Pasman L, Tan TG, Ortiz-Lopez A, Yanortsang TB, Yang L, Jupp R, Mathis D, et al: Mining the Human Gut Microbiota for Immunomodulatory Organisms. Cell 168: 928-943.e11, 2017.

24. Haber AL, Biton M, Rogel N, Herbst RH, Shekhar K, Smillie C, Burgin G, Delorey TM, Howitt MR, Katz Y, et al: A single-cell survey of the small intestinal epithelium. Nature 551: 333-339, 2017.

25. Nash AK, Auchtung TA, Wong MC, Smith DP, Gesell JR, Ross MC, Stewart CJ, Metcalf GA, Muzny DM, Gibbs RA, et al: The gut mycobiome of the Human Microbiome Project healthy cohort. Microbiome 5: 153, 2017.
26. Lloyd-Price J, Mahurkar A, Rahnavard G, Crabtree J, Orvis J, Hall AB, Brady A, Creasy HH, McCracken C, Giglio MG, et al: Strains, functions and dynamics in the expanded Human Microbiome Project. Nature 550: 61-66, 2017.

27. Rothschild D, Weissbrod O, Barkan E, Kurilshikov A, Korem T, Zeevi D, Costea PI, Godneva A, Kalka IN, Bar N, et al: Environment dominates over host genetics in shaping human gut microbiota. Nature 555: 210-215, 2018.

28. Korem T, Zeevi D, Suez J, Weinberger A, Avnit-Sagi T, Pompan-Lotan M, Matot E, Jona G, Harmelin A, Cohen N, et al: Growth dynamics of gut microbiota in health and disease inferred from single metagenomic samples. Science 349: 1101-1106, 2015.

29. Lloyd-Price J, Abu-Ali G and Huttenhower C: The healthy human microbiome. Genome Med 8: 51, 2016.

30. Hill C, Guarner F, Reid G, Gibson GR, Merenstein DJ, Pot B, Morelli L, Canani RB, Flint HJ, Salminen S, et al: Expert consensus document. The International Scientific Association for Probiotics and Prebiotics consensus statement on the scope and appropriate use of the term probiotic. Nat Rev Gastroenterol Hepatol 11: 506-514, 2014.

31. Pandey KR, Naik SR and Vakil BV: Probiotics, prebiotics and synbiotics- a review. J Food Sci Technol 52: 7577-7587, 2015.

32. Tsai YL, Lin TL, Chang CJ, Wu TR, Lai WF, Lu CC and Lai HC: Probiotics, prebiotics and amelioration of diseases. J Biomed Sci 26: 3, 2019.

33. Goodman B and Gardner H: The microbiome and cancer. J Pathol 244: 667-676, 2018.

34. Tomasetti C and Vogelstein B: Cancer etiology. Variation in cancer risk among tissues can be explained by the number of stem cell divisions. Science 347: 78-81, 2015.

35. Ashford NA, Bauman P, Brown HS, Clapp RW, Finkel AM, Gee D, Hattis DB, Martuzzi M, Sasco AJ and Sass JB: Cancer risk: Role of environment. Science 347: 727, 2015.

36. Polo A, Crispo A, Cerino P, Falzone L, Candido S, Giudice A, De Petro G, Ciliberto G, Montella M, Budillon A, et al: Environment and bladder cancer: Molecular analysis by interaction networks. Oncotarget 8: 65240-65252, 2017.

37. Falzone L, Marconi A, Loreto C, Franco S, Spandidos DA and Libra M: Occupational exposure to carcinogens: Benzene, pesticides and fibers (Review). Mol Med Rep 14: 4467-4474, 2016.

38. Anand P, Kunnumakkara AB, Sundaram C, Harikumar KB, Tharakan ST, Lai OS, Sung B and Aggarwal BB: Cancer is a preventable disease that requires major lifestyle changes. Pharm Res 25: 2097-2116, 2008.

39. Global Burden of Disease Cancer Collaboration, Fitzmaurice C, Allen C, Barber RM, Barregard L, Bhutta ZA, Brenner H, Dicker DJ, Chimed-Orchir O, Dandona R, et al: Global, Regional, and National Cancer Incidence, Mortality, Years of Life Lost, Years Lived With Disability, and Disability-Adjusted Life-years for 32 Cancer Groups, 1990 to 2015: A Systematic Analysis for the Global Burden of Disease Study. JAMA Oncol 3: 524-548, 2017.

40. Wang H, Naghavi M, Allen C, Barber RM, Bhutta ZA, Carter A, Casey DC, Charlson FJ, Chen AZ, Coates MM, et al; GBD 2015 Mortality and Causes of Death Collaborators: Global, regional, and national life expectancy, all-cause mortality, and cause-specific mortality for 249 causes of death, 1980-2015: A systematic analysis for the Global Burden of Disease Study 2015. Lancet 388: 1459-1544, 2016.

41. Rapisarda V, Salemi R, Marconi A, Loreto C, Graziano AC, Cardile V, Basile MS, Candido S, Falzone L, Spandidos DA, et al: Fluoro-edenite induces fibulin-3 overexpression in non-malignant human mesothelial cells. Oncol Lett 12: 3363-3367, 2016.

42. Rapisarda V, Ledda C, Matera S, Fago L, Arrabito G, Falzone L, Marconi A, Libra M and Loreto C: Absence of $t(14 ; 18)$ chromosome translocation in agricultural workers after short-term exposure to pesticides. Mol Med Rep 15: 3379-3382, 2017.

43. Fenga C, Gangemi S, Di Salvatore V, Falzone L and Libra M: Immunological effects of occupational exposure to lead (Review). Mol Med Rep 15: 3355-3360, 2017.

44. Vogelstein B,Papadopoulos N, Velculescu VE, Zhou S, Diaz LA Jr and Kinzler KW: Cancer genome landscapes. Science 339: 1546-1558, 2013.

45. Guarneri C, Bevelacqua V, Polesel J, Falzone L, Cannavò PS, Spandidos DA, Malaponte G and Libra M: NF- $\mathrm{B}$ inhibition is associated with OPN/MMP-9 downregulation in cutaneous melanoma. Oncol Rep 37: 737-746, 2017.

46. Salemi R, Falzone L, Madonna G, Polesel J, Cinà D, Mallardo D, Ascierto PA, Libra M and Candido S: MMP-9 as a Candidate Marker of Response to BRAF Inhibitors in Melanoma Patients With BRAFV600E Mutation Detected in Circulating-Free DNA. Front Pharmacol 9: 856, 2018. 
47. Leonardi GC, Falzone L, Salemi R, Zanghì A, Spandidos DA, Mccubrey JA, Candido S and Libra M: Cutaneous melanoma: From pathogenesis to therapy (Review). Int J Oncol 52: 1071-1080, 2018

48. Bhang HE, Ruddy DA, Krishnamurthy Radhakrishna V, Caushi JX, Zhao R, Hims MM, Singh AP, Kao I, Rakiec D, Shaw $\mathrm{P}$, et al: Studying clonal dynamics in response to cancer therapy using high-complexity barcoding. Nat Med 21: 440-448, 2015.

49. Kloor M and von Knebel Doeberitz M: The Immune Biology of Microsatellite-Unstable Cancer. Trends Cancer 2: 121-133, 2016.

50. Carter SL, Eklund AC, Kohane IS, Harris LN and Szallasi Z: A signature of chromosomal instability inferred from gene expression profiles predicts clinical outcome in multiple human cancers. Nat Genet 38: 1043-1048, 2006.

51. Dagogo-Jack I and Shaw AT: Tumour heterogeneity and resistance to cancer therapies. Nat Rev Clin Oncol 15: 81-94, 2018.

52. Falzone L, Romano GL, Salemi R, Bucolo C, Tomasello B, Lupo G, Anfuso CD, Spandidos DA, Libra M and Candido S: Prognostic significance of deregulated microRNAs in uveal melanomas. Mol Med Rep 19: 2599-2610, 2019.

53. Battaglia R, Palini S, Vento ME, La Ferlita A, Lo Faro MJ, Caroppo E, Borzì P, Falzone L, Barbagallo D, Ragusa M, et al: Identification of extracellular vesicles and characterization of miRNA expression profiles in human blastocoel fluid. Sci Rep 9: 84, 2019.

54. Basile MS, Fagone P, Mangano K, Mammana S, Magro G, Salvatorelli L, Li Destri G, La Greca G, Nicoletti F, Puleo S and Pesce A: KCNMA1 Expression is Downregulated in Colorectal Cancer via Epigenetic Mechanisms. Cancers (Basel) 11: pii: E245, 2019.

55. Falzone L, Scola L, Zanghì A, Biondi A, Di Cataldo A, Libra M and Candido S: Integrated analysis of colorectal cancer microRNA datasets: Identification of microRNAs associated with tumor development. Aging (Albany NY) 10: 1000-1014, 2018.

56. McCubrey JA, Fitzgerald TL, Yang LV, Lertpiriyapong K, Steelman LS, Abrams SL, Montalto G, Cervello M, Neri LM, Cocco L, et al: Roles of GSK-3 and microRNAs on epithelial mesenchymal transition and cancer stem cells. Oncotarget 8: 14221-14250, 2017.

57. Falzone L, Candido S, Salemi R, Basile MS, Scalisi A, McCubrey JA, Torino F, Signorelli SS, Montella M and Libra M: Computational identification of microRNAs associated to both epithelial to mesenchymal transition and NGAL/MMP-9 pathways in bladder cancer. Oncotarget 7: 72758-72766, 2016.

58. Hafsi S, Candido S, Maestro R, Falzone L, Soua Z, Bonavida B, Spandidos DA and Libra M: Correlation between the overexpression of Yin Yang 1 and the expression levels of miRNAs in Burkitt's lymphoma: A computational study. Oncol Lett 11: 1021-1025, 2016.

59. Falzone L, Lupo G, Rosa GRM, Crimi S, Anfuso CD, Salemi R, Rapisarda E, Libra M and Candido S: Identification of Novel MicroRNAs and Their Diagnostic and Prognostic Significance in Oral Cancer. Cancers (Basel) 11: pii: E610, 2019.

60. Falzone L, Salemi R, Travali S, Scalisi A, McCubrey JA, Candido S and Libra M: MMP-9 overexpression is associated with intragenic hypermethylation of MMP9 gene in melanoma. Aging (Albany NY) 8: 933-944, 2016

61. Dy GK and Adjei AA: Understanding, recognizing, and managing toxicities of targeted anticancer therapies. CA Cancer J Clin 63: 249-279, 2013

62. McGranahan N and Swanton C: Biological and therapeutic impact of intratumor heterogeneity in cancer evolution. Cancer Cell 27: 15-26, 2015.

63. Thorsson V, Gibbs DL, Brown SD, Wolf D, Bortone DS, Ou Yang TH, Porta-Pardo E, Gao GF, Plaisier CL, Eddy JA, et al; Cancer Genome Atlas Research Network: The Immune Landscape of Cancer. Immunity 48: 812-830.e14, 2018.

64. Presti M, Mazzon E, Basile MS, Petralia MC, Bramanti A, Colletti G, Bramanti P, Nicoletti F and Fagone P: Overexpression of macrophage migration inhibitory factor and functionally-related genes, D-DT, CD74, CD44, CXCR2 and CXCR4, in glioblastoma. Oncol Lett 16: 2881-2886, 2018

65. Mangano K, Mazzon E, Basile MS, Di Marco R, Bramanti P, Mammana S, Petralia MC, Fagone P and Nicoletti F: Pathogenic role for macrophage migration inhibitory factor in glioblastoma and its targeting with specific inhibitors as novel tailored therapeutic approach. Oncotarget 9: 17951-17970, 2018.
66. Basile MS, Mazzon E, Russo A, Mammana S, Longo A Bonfiglio V, Fallico M, Caltabiano R, Fagone P, Nicoletti F, et al: Differential modulation and prognostic values of immune-escape genes in uveal melanoma. PLoS One 14: $\mathrm{e} 0210276,2019$.

67. Emens LA, Ascierto PA, Darcy PK, Demaria S, Eggermont AMM, Redmond WL, Seliger B and Marincola FM: Cancer immunotherapy: Opportunities and challenges in the rapidly evolving clinical landscape. Eur J Cancer 81: 116-129, 2017.

68. Toh HC: Cancer immunotherapy-the end of the beginning. Linchuang Zhongliuxue Zazhi 7: 12, 2018.

69. Roy S and Trinchieri G: Microbiota: A key orchestrator of cancer therapy. Nat Rev Cancer 17: 271-285, 2017.

70. Nayak RR and Turnbaugh PJ: Mirror, mirror on the wall: Which microbiomes will help heal them all? BMC Med 14: 72, 2016

71. Fessler JL and Gajewski TF: The Microbiota: A New Variable Impacting Cancer Treatment Outcomes. Clin Cancer Res 23: 3229-3231, 2017.

72. Schwabe RF and Jobin C: The microbiome and cancer. Nat Rev Cancer 13: 800-812, 2013

73. Gopalakrishnan V, Helmink BA, Spencer CN, Reuben A and Wargo JA: The Influence of the Gut Microbiome on Cancer, Immunity, and Cancer Immunotherapy. Cancer Cell 33: 570-580, 2018.

74. Routy B, Le Chatelier E, Derosa L, Duong CPM, Alou MT, Daillère R, Fluckiger A, Messaoudene M, Rauber C, Roberti MP, et al: Gut microbiome influences efficacy of PD-1-based immunotherapy against epithelial tumors. Science 359: 91-97, 2018

75. Gopalakrishnan V, Spencer CN, Nezi L, Reuben A, Andrews MC Karpinets TV, Prieto PA, Vicente D, Hoffman K, Wei SC, et al: Gut microbiome modulates response to anti-PD-1 immunotherapy in melanoma patients. Science 359: 97-103, 2018.

76. Matson V, Fessler J, Bao R, Chongsuwat T, Zha Y, Alegre ML, Luke JJ and Gajewski TF: The commensal microbiome is associated with anti-PD-1 efficacy in metastatic melanoma patients. Science 359: 104-108, 2018.

77. Chen Q, Wang C, Chen G, Hu Q and Gu Z: Delivery Strategies for Immune Checkpoint Blockade. Adv Healthc Mater 7: e1800424, 2018.

78. Buchbinder EI and Desai A: CTLA-4 and PD-1 Pathways: Similarities, Differences, and Implications of Their Inhibition. Am J Clin Oncol 39: 98-106, 2016.

79. Falzone L, Salomone S and Libra M: Evolution of Cancer Pharmacological Treatments at the Turn of the Third Millennium. Front Pharmacol 9: 1300, 2018

80. Mego M, Holec V, Drgona L, Hainova K, Ciernikova S and Zajac V: Probiotic bacteria in cancer patients undergoing chemotherapy and radiation therapy. Complement Ther Med 21: 712-723, 2013 .

81. Maria-Aggeliki KS, Nikolaos KL, Kyrias GM and Vassilis KE: The potential clinical impact of probiotic treatment for the prevention and/or anti-inflammatory therapeutic effect against radiation induced intestinal mucositis. A review. Recent Pat Inflamm Allergy Drug Discov 3: 195-200, 2009.

82. Rondanelli M, Faliva MA, Perna S, Giacosa A, Peroni G and Castellazzi AM: Using probiotics in clinical practice: Where are we now? A review of existing meta-analyses. Gut Microbes 8: 521-543, 2017.

83. Zitvogel L, Ma Y, Raoult D, Kroemer G and Gajewski TF: The microbiome in cancer immunotherapy: Diagnostic tools and therapeutic strategies. Science 359: 1366-1370, 2018.

84. Vanderhoof JA and Young R: Probiotics in the United States. Clin Infect Dis 46 (Suppl 2): S67-S72, discussion S144-S151, 2008.

85. Redman MG, Ward EJ and Phillips RS: The efficacy and safety of probiotics in people with cancer: A systematic review. Ann Oncol 25: 1919-1929, 2014

86. Peterson DE, Boers-Doets CB, Bensadoun RJ, Herrstedt J and Committee EG; ESMO Guidelines Committee: Management of oral and gastrointestinal mucosal injury: ESMO Clinical Practice Guidelines for diagnosis, treatment, and follow-up. Ann Oncol 26 (Suppl 5): v139-v151, 2015.

87. Lalla RV, Bowen J, Barasch A, Elting L, Epstein J, Keefe DM, McGuire DB, Migliorati C, Nicolatou-Galitis O, Peterson DE, et al Mucositis Guidelines Leadership Group of the Multinational Association of Supportive Care in Cancer and International Society of Oral Oncology (MASCC/ISOO): MASCC/ISOO clinical practice guidelines for the management of mucositis secondary to cancer therapy. Cancer 120: 1453-1461, 2014. 
88. Gianotti L, Morelli L, Galbiati F, Rocchetti S, Coppola S, Beneduce A, Gilardini C, Zonenschain D, Nespoli A and Braga M: A randomized double-blind trial on perioperative administration of probiotics in colorectal cancer patients. World J Gastroenterol 16: 167-175, 2010.

89. Demers M, Dagnault A and Desjardins J: A randomized double-blind controlled trial: Impact of probiotics on diarrhea in patients treated with pelvic radiation. Clin Nutr 33: 761-767, 2014

90. Mego M, Chovanec J, Vochyanova-Andrezalova I, Konkolovsky P, Mikulova M, Reckova M, Miskovska V, Bystricky B, Beniak J, Medvecova L, et al: Prevention of irinotecan induced diarrhea by probiotics: A randomized double blind, placebo controlled pilot study. Complement Ther Med 23: 356-362, 2015.

91. Theodoropoulos GE, Memos NA, Peitsidou K, Karantanos T, Spyropoulos BG and Zografos G: Synbiotics and gastrointestinal function-related quality of life after elective colorectal cancer resection. Ann Gastroenterol 29: 56-62, 2016.

92. Consoli ML, da Silva RS, Nicoli JR, Bruña-Romero O, da Silva RG, de Vasconcelos Generoso S and Correia MI: Randomized Clinical Trial: Impact of Oral Administration of Saccharomyces boulardii on Gene Expression of Intestinal Cytokines in Patients Undergoing Colon Resection. JPEN J Parenter Enteral Nutr 40: 1114-1121, 2016.

93. Flesch AT, Tonial ST, Contu PC and Damin DC: Perioperative synbiotics administration decreases postoperative infections in patients with colorectal cancer: A randomized, double-blind clinical trial. Rev Col Bras Cir 44: 567-573, 2017.

94. Goldin BR, GualtieriLJ and Moore RP: The effect of Lactobacillus GG on the initiation and promotion of DMH-induced intestinal tumors in the rat. Nutr Cancer 25: 197-204, 1996.

95. Banna GL, Torino F, Marletta F, Santagati M, Salemi R, Cannarozzo E, Falzone L, Ferraù F and Libra M: Lactobacillus rhamnosus GG: An Overview to Explore the Rationale of Its Use in Cancer. Front Pharmacol 8: 603, 2017.
96. Lee CS, Ryan EJ and Doherty GA: Gastro-intestinal toxicity of chemotherapeutics in colorectal cancer: The role of inflammation. World J Gastroenterol 20: 3751-3761, 2014.

97. Khailova L, Baird CH, Rush AA, Barnes C and Wischmeyer PE: Lactobacillus rhamnosus GG treatment improves intestinal permeability and modulates inflammatory response and homeostasis of spleen and colon in experimental model of Pseudomonas aeruginosa pneumonia. Clin Nutr 36: 1549-1557, 2017.

98. Wang Y, Liu L, Moore DJ, Shen X, Peek RM, Acra SA, Li H, Ren X, Polk DB and Yan F: An LGG-derived protein promotes IgA production through upregulation of APRIL expression in intestinal epithelial cells. Mucosal Immunol 10: 373-384, 2017.

99. Fong FLY,Kirjavainen PV and El-Nezami H: Immunomodulation of Lactobacillus rhamnosus GG (LGG)-derived soluble factors on antigen-presenting cells of healthy blood donors. Sci Rep 6: 22845,2016

100. Vivarelli S, Salemi R, Candido S, Falzone L, Santagati M, Stefani S, Torino F, Banna GL, Tonini G and Libra M: Gut Microbiota and Cancer: From Pathogenesis to Therapy. Cancers (Basel) 11: pii: E38, 2019.

101. Riehl TE, Alvarado D, Ee X, Zuckerman A, Foster L, Kapoor V, Thotala D, Ciorba MA and Stenson WF: GG protects the intestinal epithelium from radiation injury through release of lipoteichoic acid, macrophage activation and the migration of mesenchymal stem cells. Gut 68: 1003-1013, 2018.

This work is licensed under a Creative Commons Attribution-NonCommercial-NoDerivatives 4.0 International (CC BY-NC-ND 4.0) License. 